\title{
EXTENSÃO E PRÁTICA SOCIAL: EXPERIÊNCIA COM OFICINAS DE SUSTENTABILIDADE EM ESCOLA RURAL
}

\author{
Tatiane Almeida Netto ${ }^{1}$, Clayton Hillig ${ }^{2}$, Daiane Loreto de Vargas ${ }^{3}$ \\ ${ }^{1}$ Engenheira Florestal, Mestranda em Extensão Rural, PPGExR/UFSM., tatinetto@yahoo.com.br \\ ${ }^{2}$ UFSM/Professor, hillig@smail.ufsm.br \\ 3 UFSM/aluna doutorado PPGExR, loretodevargas@gmail.com
}

http://dx.doi.org/10.5902/223613087154

\section{RESUMO}

Este trabalho descreve a vivência das ações de extensão com práticas pedagógicas em escola Rural com as oficinas de sustentabilidade na Escola Rural Pedro Lovato/RS-Brasil. A experiência resulta em práticas que buscam refletir a situação ambiental e social, com o intuito de oferecer e compartilhar com os alunos tarefas educacionais e científicas abordando a sustentabilidade e promoção de um processo de conscientização. As oficinas elaboradas partem do conceito de Paulo Freire na construção de uma educação popular, envolvendo o aluno nas mais diversas formas de atividades, na ação prática, no estímulo à descoberta, ao pensar, ao criar, à experimentação e o debate, buscando a autonomia do aluno através da criticidade a ser desenvolvida. Através das dinâmicas em grupo foram desenvolvidas dez oficinas, englobando temas de sustentabilidade, bem estar animal, manejo de ordenha, preservação de flora, fauna, resgate histórico cultural e agroecologia, com a construção de composteira e horta suspensa. As atividades foram desenvolvidas no mês de junho 2012, pelos discentes da turma 11 e 12 da disciplina de Extensão Rural da UFSM, sobre coordenação do professor responsável pela disciplina, onde os resultados alcançados permitiram aos alunos, tanto acadêmicos do curso superior quanto os de ensino fundamental, a aproximação e interação entre o universo escolar e o meio acadêmico, proporcionando a troca de saberes necessária para o desenvolvimento de uma prática social que corrobore no desenvolvimento de um processo de intervenção de caráter educativo e transformador.

Palavras chaves: extensão, sustentabilidade, educação popular, prática social.

\section{ABSTRACT}

This paper describes the experience of extension activities with pedagogical practices in school workshops with the Rural Sustainability in Rural School Pedro Lovato / RS-Brazil. The experience results in practices that seek to reflect the environmental and social situation, in order to offer and share with the students educational and scientific tasks addressing sustainability and promoting an awareness process. The workshops run of the concept developed by Paulo Freire in building a popular education, involving students in various forms of activities, in practical action, encouraging discovery, to think, to create, to experimentation and discussion, seeking autonomy student through criticality being developed. Through group dynamics were developed ten workshops covering topics of sustainability, animal welfare, milking management, preservation of flora, fauna, cultural and historical restoration ecology, with the construction of compost and garden suspended. The activities were conducted in June 2012, by students of class 11 and 12 of the 
discipline of Agricultural Extension UFSM on coordination the teacher responsible for the course, where the results obtained allowed the students both the academic college as the elementary school, the proximity and interaction between the school environment and academia, providing the exchange of knowledge necessary for the development of a social practice that corroborates in developing an intervention process educative and transformative.

Keywords: extension, sustainability, popular education, social practice.

\section{INTRODUÇÃO}

As universidades brasileiras, principalmente as públicas, no decorrer dos tempos mudaram a visão de sua extensão, não é somente uma extensão de cursos, serviços e assistencial onde hoje podemos vê-la além, como mão dupla entre a universidade e a sociedade estabelecendo a sistematização de trocas de saberes resultando na produção de um conhecimento com participação da sociedade e democratização do saber.

Tendo em vista a prática extensionista da Universidade Federal de Santa Maria, o município de Novos Cabrais, procurou a mesma para a inserção de atividades na Escola rural de ensino Fundamental Pedro Lovato. A proposta inicial do poder público do município de Novos Cabrais é demonstrar a comunidade novas potencialidades de cultivo, ou seja, a diversificação em áreas de produção de tabaco, haja vista, a intencionalidade do País junto à Convenção-Quadro para o Controle do Tabaco (CQCT). A escola encontra-se em situação vulnerável em detrimento da comunidade ser composta de oitenta famílias cuja principal atividade econômica é a agricultura familiar, tendo como foco o cultivo do fumo.

As ações de extensão com práticas pedagógicas surgem na escola Pedro Lovato através da disciplina de Extensão Rural, Departamento de Educação Agrícola e Extensão Rural da Universidade Federal de Santa Maria e busca criar mecanismos capazes de garantir a aproximação e interação entre o universo escolar da E.E.E.F. Pedro Lovato e o meio acadêmico da UFSM fortalecendo o compromisso social da universidade e da extensão universitária como uma prática social.

As ações de extensão proporcionam a troca de saberes necessária para o desenvolvimento de uma prática social que corrobore no desenvolvimento de um processo de intervenção de caráter educativo e transformador. Através da contextualização da realidade, com a participação de alunos de graduação do 70 semestre da Medicina Veterinária, e de formação fundamental do 1ำ ao 9을 ano, busca-se com esta ação a indissociabilidade do Ensino, da Pesquisa e da Extensão com a inserção na localidade de Cortado, Município de Novos Cabrais/RS.

“...Trata-se, em suma, de um novo paradigma curricular no qual é inevitável a indissociabilidade ensino-pesquisa-extensão enquanto eixo de formação do estudante, de uma perspectiva na qual a graduação vai além da mera transmissão para se transformar em espaço de construção do conhecimento,em que o estudante passa a ser sujeito, crítico e participativo, para o qual a flexibilização aparece como um meio de viabilização...( Fórum de Pró-Reitores de Extensão das Universidades Públicas Brasileiras,2006)." 
A E.E.E.F. Pedro Lovato foi fundada em 1953, está localizada no centro da localidade de Cortado no município de Novo Cabrais, próxima a Igreja Católica (Paróquia São Claudio), Clube Esportivo, e demais dependências públicas como mercado, campo de futebol, cemitério, lojas, etc, sendo a única Escola de Ensino Fundamental da localidade. Atualmente consta de 12 professores, 3 funcionários e 85 alunos.

A comunidade escolar, pertencente à localidade de Cortado, está composta de oitenta famílias oriundas do meio rural, cuja principal atividade econômica é agricultura familiar, tendo como destaque o cultivo do fumo e soja. A localidade do Cortado está localizada ao sudoeste do município de Novo Cabrais, fazendo divisa com os municípios de Paraíso do Sul e Cerro Branco. As principais características das propriedades, como área, posse e permanência no local evidenciam a característica da agricultura familiar, da localidade onde 50\% compreendem até 15 ha de área total, $45 \%$ são proprietários das terras e residem em média no local 41 anos (Estudo da realidade rural-localidade Cortado-Novos Cabrais/RS, 2011).

A localidade do Cortado é uma das primeiras regiões povoadas de Novo Cabrais. Possui uma população de aproximadamente 1.000 Habitantes em sua maioria de origem italiana. 0 acesso à localidade se dá através da RSC 287, tendo a localidade uma extensão de aproximadamente $9 \mathrm{Km}$ com um relevo privilegiado e uma cultura muito forte e rica.

As oficinas de sustentabilidade têm como objetivo a contribuição para a construção de um ambiente educativo que considere a relação com o meio ambiente, a cultura e os saberes próprios dos estudantes. Utiliza-se da educação popular para o resgate da cidadania e a necessidade da inclusão em todos os sentidos e do conceito de educação ambiental na construção do comprometimento socioambiental almejado pela escola rural.

A escola rural deve ser tratada diferentemente da escola urbana, o contexto, as realidades e as necessidades são diferentes, a legislação brasileira prevê essa diferença e um planejamento vinculado ao meio, no momento em que a Lei de Diretrizes e Bases da Educação Nacional (LDB) promove a desvinculação da escola rural e urbana, exigindo um planejamento interligado à vida rural e uma educação com dimensões sócio-políticas e culturais com base na cidadania e na prática social. (Brasil/MEC, LDB 9.394/96).

Devemos compreender a especificidade do campo, os vínculos entre território, terra, lugar e escola, que determinam a formação social, política, cultural e a identidade dos povos do campo sem a devida compreensão não seremos capazes de tornar a escola um lugar de formação (ARROYO, 2007). Neste sentido, vimos a compreender o campo como espaço de vida, multidimensional, onde se manifestam e realizam as relações sociais, a educação, cultura, produção, trabalho, infraestrutura, organização política e a construção de mercado, que é produto das relações sociais que se desenvolvem em conjunto e não podem ser analisados em separado sem construção de dicotomias.

\section{METODOLOGIA}

A metodologia utilizada para desenvolver das oficinas foi à pesquisa- ação onde utilizamos conceito de simetria discursiva, desenvolvido por Paulo Freire (FREIRE, P., 1988,1997), na qual as práticas ocorrem através de diálogos, interações entre os alunos, conhecimento partilhado com o aluno e não somente direcionado a ele, priorizando a inserção do aluno no processo educativo, promovendo a inserção social contextualizada, com a temática da educação 
ambiental e a transversalidade ao modo de vida rural englobando temas de bem estar animal, manejo de ordenha, preservação de flora, fauna, resgate histórico cultural e agroecologia, com a construção de composteira e horta suspensa.

As oficinas foram realizadas em dois dias de campo na E.E.E.F. Pedro Lovato, no dia 14/junho de 2012 realizou-se cinco oficinas pelos alunos da Graduação do curso de Medicina Veterinária com os alunos da escola, sendo estas: 10 Oficina- Tema: fauna: Trabalhando com sucata- séries iniciais; 2 o Oficina- Tema: Patrimônio histórico cultural-Caderno de receita- 5série; 3ำ Oficina- Tema: preservação da flora nativa-Mata ciliar- 8o série; 4Oficina- Tema: Agroecologia-

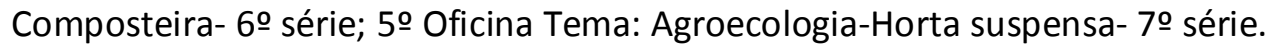

No dia 21 de junho foram realizadas mais cinco oficinas pelos alunos da Graduação do curso de Medicina Veterinária com os alunos da escola, sendo estas: 10 Oficina- Tema: Bem estar animal: Bem estar animal- séries iniciais; 2o Oficina- Tema: Pecuária -Manejo de ordenha em bovinos de leite- 5série; 3 Oficina- Tema: Sustentabilidade- Energia solar- 6 série; 4OficinaTema: fauna- Construção de comedouros para aves - 70 série; 5ㅇ Oficina Tema: sustentabilidadeÁgua é vida- 8 o série.

Todas as oficinas realizadas surgiram como propostas dos alunos de graduação com orientação do professor responsável pela disciplina, englobam o modo de vida rural e partem do princípio de que a educação, e essencialmente a educação do campo, são processos de construção de conhecimentos que procuram contribuir com o desenvolvimento dos territórios do campo como espaço de vida.

\section{RESULTADOS E DISCUSSÃO}

Para o desenvolvimento do campo é necessário uma política educacional que atenda suas especificidades, entenda os sujeitos como atores e não somente como usuários, a educação pode vir a promover as condições políticas essenciais para o desenvolvimento do território, composto pelas particularidades, na sua organização por meio do trabalho familiar. (FERNADES, 2005).

A partir da especificidade do campo faremos uma análise dos conceitos que embasaram a realização das oficinas de sustentabilidade na escola E.E.E.F. Pedro Lovato que servem para a construção de um processo reflexivo por parte da direção de escola professores e funcionários para uma mudança no procedimento pedagógico. Os conceitos abrangem a educação onde a mesma é vista como o meio dos seres se realizarem em uma sociedade, buscando a sustentabilidade da vida refletindo criticamente através de novos conhecimentos. A educação é o caminho da mudança da superação da dominação e da exclusão (DUARTE, 2002).

O conceito de educação popular segundo Paulo Freire parte da realidade das práticas sociais, leva em conta o local, a região em que vive o educando e tem como objetivo primordial a inserção deste no processo educativo, de modo vivo e dinâmico, incluído numa política de desenvolvimento.

Tornar popular a educação compreende sua universalização e democratização em diferentes níveis tornando-a de fato acessível às camadas populares pela via do conhecimento e da cidadania, frente às condições necessárias a transformação social e a emancipação humana, finalidade da ação político-pedagógico. É uma estratégia de construção da participação popular para o redirecionamento da vida social. 
A Educação Popular é uma educação comprometida e participativa, orientada pela perspectiva de realização de todos os direitos do povo, o processo-ensino-aprendizagem é visto como ato de conhecimento e transformação social, sendo pautado na perspectiva política, sua principal característica é utilizar o saber da comunidade como matéria prima para o ensino, aprender a partir do conhecimento do sujeito e ensinar a partir de palavras e temas geradores do cotidiano dele.

Educar é saber "ler" o mundo, conhecê-lo para transformá-lo e ao transformá-lo, conhecêlo (GADOTTI, 2003). Para desenvolvermos a educação precisamos de metodologias participativas, da hermenêutica, da pedagogia da complexidade voltada para a problematização dos diferentes sentidos, interesses e forças sociais que se organizam em torno das questões ambientais. Ao reinterpretar as interpretações vigentes, esta prática educativa abre um campo de novas possibilidades de compreensão e auto compreensão, no sentido do reposicionamento e engajamento dos sujeitos na problemática ambiental (CARVALHO, 2003).

As oficinas trazem sua contribuição para a construção de um ambiente educativo que considere a relação com o meio ambiente, a cultura e os saberes próprios dos estudantes. Utilizamos na metodologia das oficinas o conceito de educação ambiental na construção do comprometimento socioambiental almejado pela escola rural. As práticas de Educação ambiental no campo tem como propósito o desenvolvimento rural sustentável, foi abordada procurando trazer a vivência dos alunos do meio rural, a integração com a natureza, nas práticas e oficinas e nas atividades e trabalhos em grupo.

A educação ambiental aponta para propostas pedagógicas centradas na conscientização, mudança de comportamento, desenvolvimento de competências, capacidade de avaliação e participação dos educandos. A relação entre meio ambiente e educação assume um papel cada vez mais desafiador demandando a emergência de novos saberes para apreender processos sociais complexos e riscos ambientais que se intensificam (JACOBI, 2004 p.28).

A educação deve preparar as novas gerações para aceitar as incertezas e para novas mentalidades capazes de compreender as complexas inter-relações, gerar um pensamento aberto às especificidades, possibilidade de construir e reconstruir num processo contínuo de novas leituras e interpretações um processo dialógico para a construção de uma nova racionalidade e emancipação que permita novas formas e reapropriação do mundo (JACOBI, 2004).

A inserção da agroecologia nas práticas se deve ao fato de que a nova extensão rural busca a aproximação dos saberes locais, devendo ser visualizada como um processo endógeno de conhecimento, sistêmico e multidisciplinar. Paulo Freire propôs o estabelecimento de um modelo dialético entre agricultor e extensionista, baseado nas trocas de saber e na (re) valorização da cultura local. Esse modelo deve ser utilizado na construção de metodologias, compostas por uma visão agroecológica que valorizem o saber popular e a construção participativa (CAPORAL F. R, RAMOS, L. F,2006).

Nas bases conceituais da agroecologia citam-se Caporal, Costabeber, Gliessman, Altieri que afirmam ter a ciência da agroecologia um enfoque na agricultura mais relacionado ao meio ambiente, seu equilíbrio, e mais sensível socialmente, busca a produção, mas também a sustentabilidade ecológica do sistema de produção que vai muito mais além da unidade de produção abrangendo os ecossistemas.

A agroecologia é o campo de conhecimento e investigação para auxiliar na operação da nova extensão rural focalizando suas estratégias para a ascensão do desenvolvimento rural sustentável. Esta é definida como a "ciência ou disciplina científica que apresenta uma série de princípios, conceitos e metodologias para estudar, analisar, dirigir, desenhar e avaliar 
agroecossistemas, com o propósito de permitir a implantação e o desenvolvimento de estilos de agricultura com maiores níveis de sustentabilidade no curto, médio e longo prazos" (Altieri, 1995, p.26).

A construção da nova extensão rural iniciou a tomar forma a partir do momento que começaram a serem incorporados aos debates os novos anseios da sociedade rural e urbana, com relação a um novo projeto de desenvolvimento, e na medida em que foram buscadas orientações teóricas baseadas em um paradigma alternativo ao convencional. Para que realmente esta proposta de nova extensão rural se imponha é necessário o apoio de instituições de ensino e pesquisa, para que se possa trabalhar o desenvolvimento rural sob o ponto de vista agroecológico.

\section{PROBLEMATIZAÇÕES DA EDUCAÇÃO RURAL}

O discurso desenvolvimentista e a modernização da agricultura atingiu também a educação, onde o rural é visto como uma extensão da industrialização e potencial de liberação de mão de obra para o setor urbano. Porém a ruralidade contemporânea aponta novas dimensões um novo espaço mercantilizado de bens e serviços, novas possibilidades de negócios, tanto imobiliários quanto voltados ao turismo e lazer, valorizando bens não tangíveis, como paisagem e cultura.

Para tanto, é necessária à introdução de uma educação no campo voltada ao paradigma da sustentabilidade e uma nova perspectiva da ruralidade, uma preocupação com desenvolvimento humano, social e o ambiental. No desenvolvimento de ações pedagógicas participativas devemos prever a educação como um processo de emancipação, buscando a construção reflexiva e a autonomia do sujeito num processo crítico e participativo, respeitando e utilizando o saber popular como fonte e resultado da aprendizagem (CALDART, R. 2004).

Atualmente a educação do campo encontra-se fragmentada em seu processo curricular, desvinculada de um contexto histórico e distanciada da realidade na qual o sujeito vive, ao educando é repassado um pensamento unidimensional, sem destacar e fazer perceber a visão geral, e é nesse sentido que se busca a complexidade ambiental, para uma nova compreensão do mundo, que incorpore o limite do conhecimento e da incompletude do ser, onde se constrói e se aprende através do processo dialógico de saberes, na hibridação da ciência, das tecnologias e dos saberes populares (LEFF, 2003).

A complexidade ambiental necessita de uma pedagogia do ambiente e de um ambiente da pedagogia para engajar-se com a vida do campo e, assim, comprometer-se com a igualdade e justiça social e com valores como a solidariedade capazes de selarem um novo contrato solidário entre os sujeitos sociais e a natureza. Identifica-se carência de uma ciência apta para confrontar as questões da sustentabilidade para afrontar os problemas da complexidade é necessário um enfoque distinto da disciplina científica tradicional, capaz de integrar uma pluralidade de conhecimentos e perspectivas (FUNTOWICZ E DE MARCHI, 2000).

Segundo Silva (2004), nos dias atuais, a educação é vista como uma responsabilidade social dos governantes perante a população, a escola básica é o espaço para aquisição de habilidades competências e conhecimentos fundamentais ao exercício da cidadania possibilitando a construção da dignidade humana. A escola é o meio para o desenvolvimento sustentável no campo, através dela podem ocorrer mudanças no paradigma social. 


\section{CONCLUSÕES}

Ao analisarmos as mudanças e transformações decorrentes da prática social das oficinas de sustentabilidade na escola, vislumbramos o diálogo, a troca de saberes, a ação comunicativa como um ato de transformação social nas dependências da escola, na rotina escolar e principalmente na estrutura pedagógica da escola. Tais ações propuseram a direção escolar buscar por uma maior compreensão da realidade da comunidade escolar.

Na prática social em que as normas sociais se constituem a partir da convivência entre sujeitos prevalece a ação comunicativa tendo em vista que o homem não reage simplesmente a estímulos do meio, mas atribui um sentido às suas ações e, graças à linguagem, é capaz de comunicar percepções e desejos, Habermas vislumbra a possibilidade de que, através do diálogo o homem possa retomar o seu papel de sujeito (GONÇALVES, 1999).

A transformação social implica em coparticipação dos diferentes sujeitos envolvidos no processo, atuando como protagonistas em um propósito de (re) construção social. Vista desta forma, a participação, deve ser concebida como um ato interativo na perspectiva de conhecer o contexto, no qual, se encontram inseridos as situações que precisam de intervenção e as alternativas para superação, utilizando para esta finalidade a mediação e o ato comunicativo.

Tratam-se, as ações realizadas, de um processo de reflexão-ação, característico dos processos de comunicação marcados pela participação ativa dos sujeitos envolvidos e pela valorização do saber local que se inter-relaciona ao saber científico. O desenvolvimento das oficinas proporcionou aos alunos da escola Pedro Lovato um novo contexto de aprendizagem sustentada na educação popular permitindo a apropriação de conhecimentos científicos e tecnológicos aproximando os mundos da educação básica e do ensino superior.

Entende-se que a transformação das relações dos grupos humanos com o meio ambiente está inserida dentro do contexto da transformação da sociedade. A educação popular pode ser um processo de mediação educativa alicerçada ao espírito agroecológico. Neste sentido, este trabalho compreende a importância de trabalhar com crianças e jovens rurais, pois se entende como fundamental prepará-los para permanecer na agricultura familiar de forma pluriativa, apropriando-se de conhecimentos que favoreçam desenvolver atividades mais sustentáveis e que superem os atuais impasses econômicos, sociais e ambientais.

\section{REFERÊNCIAS BIBLIOGRÁFICAS}

ALTIERI, M. A. Agroecologia: a dinâmica produtiva da agricultura sustentável 2. ed. Porto Alegre: Ed. da Universidade/UFRGS, 2000

ARROYO, M.G. Políticas de formação de educadores(as) do campo. Cad. Cedes, Campinas, vol. 27, n. 72, p. 157-176, maio/ago. 2007.

BRASIL. Lei no 9.394, de 20 de dezembro de 1996. Lei de Diretrizes e Bases da Educação

Nacional, Brasília, DF, 20 dez. 1996. Disponível em: < http://portal.mec.gov.br/arquivos/pdf/ldb.pdf > Acesso em 21 jul. 2011.

CALDART, R. Por uma educação do campo: traços de uma identidade em construção. In: ARROYO, M.G.; CALDART, R.; MOLINA, M. Por uma educação do campo. Petrópolis: Vozes, 2004.

CAPORAL F. R, RAMOS, L. F. Da extensão rural convencional à extensão rural para o desenvolvimento sustentável: enfrentar desafios para romper a inércia. Brasília, setembro de 2006. (texto em fase de publicação) 
CARVALHO, I. "Os sentidos do ambiental: a contribuição da hermenêutica à pedagogia da complexidade". LEFF, E. (Coord.). A Complexidade Ambiental. São Paulo: Cortez Editora,2003.

DUARTE, R. Adorno/Horkheimer e a dialética do esclarecimento. Rio de Janeiro: Jorge Zahar, 2002.

Estudo da realidade rural-localidade Cortado-Novos Cabrais/RS, Dados de campo Grupo de pesquisa em Extensão Rural Aplicada/UFSM, 2011. (texto em fase de publicação)

FERNANDES, B.M. Os campos da pesquisa em educação do campo: espaço e território como categorias essenciais. I Encontro Nacional de Pesquisa em Educação do Campo, Brasília, set. 2005.

FÓRUM DE PRÓ-REITORES DE EXTENSÃO DAS UNIVERSIDADES PÚBLICAS BRASILEIRAS Indissociabilidade ensino-pesquisa-extensão e a flexibilização curricular: uma visão da extensão /. Porto Alegre : UFRGS ;Brasília : MEC/SESu, 2006)."

FREIRE, P. Pedagogia do oprimido. Rio de Janeiro: Paz e Terra, 1988, 18 a edição.

. Pedagogia da autonomia. Saberes necessários à prática educativa. 3. ed. Rio de

Janeiro: Paz e Terra, 1997.

Funtowicz e De Marchi, Ciencia Posnormal, Complejidad Reflexiva y Sustentabilidad. In: Leff, E. (ed), La Complejidad Ambiental, Siglo XXI, Mexico,2000.

GADOTTI, M. Saber aprender: um olhar sobre Paulo Freire e as perspectivas atuais da educação.

In: LINHARES, C. \& TRINDADE, M. N. (Org.) Compartilhando o mundo com Paulo Freire. São Paulo: Cortez, 2003.

GONÇALVES,M.A.S. Teoria da ação comunicativa de Habermas: Possibilidades de uma ação educativa de cunho interdisciplinar na escola. Educação \& Sociedade, ano XX, no 66, Abril/99.

JACOBI, P. Educação e meio ambiente - transformando as práticas. Revista brasileira de educação ambiental / Rede Brasileira de Educação Ambiental. Brasília: Rede Brasileira de Educação Ambiental, 2004.

LEFF,H. La complejidad ambiental Mexico: Siglo XXI, 2 ed. 2003 .

SILVA, M. do S. Educação do Campo e Desenvolvimento: uma relação construída ao longo da história. $2004 . \quad$ Disponível em:< http://www.contag.org.br/imagens/f299Educacao_do_Campo_e_Desenvolvimento_Sustentavel.p df> Acesso em: 10 jun.2011. 